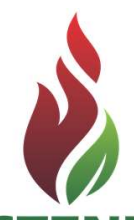

SUSTENERE

Publishing Corporation
QRRBAM

Journals Homepage:

www.sustenere.co/journals

\section{VIABILIDADE ECONÔMICA E SIMULAÇÃO DE MONTE CARLO DA PRODUÇÃO DE BIODIESEL DE RESÍDUOS DE SOJA}

\section{RESUMO}

O presente trabalho tem como objetivo realizar uma análise de viabilidade financeira, complementada por simulações de risco da implantação e da operação de uma usina produtora de biodiesel, a partir de resíduos de soja do Porto de Paranaguá, visando suprir parte da demanda por combustíveis e, consequentemente, reduzir problemas e desperdícios ocasionados pelo descarte inadequado desta oleaginosa. A análise financeira foi realizada mediante os métodos tradicionais de avaliação de investimentos; para análise de risco, utilizouse a técnica de simulação de Monte Carlo. A taxa mínima de atratividade (TMA) considerada no estudo de caso foi de $7,25 \%$ ao ano. A partir da análise financeira, estima-se a obtenção dos seguintes resultados: payback no $5^{\circ}$ ano; valor presente líquido (VPL) de $R \$ 1.089 .537,56$ e taxa de retorno interna (TIR) de $27 \%$ ao ano. O resultado das simulações indicou para a variável de saída (VPL) valor médio de $R \$$ 296.303,13. Como resultado final, a simulação mostra que haveria $18,8 \%$ de chances de o investimento não oferecer o retorno mínimo esperado pelo empresário, dependendo da situação adotada. Ressalta-se a importância das técnicas de simulação na geração de informações imprescindíveis para a tomada de decisões.

PALAVRAS-CHAVES: Viabilidade Econômica; Simulação de Risco; Porto de Paranaguá; Resíduos de Soja; Biodiesel.

\section{ECONOMIC VIABILITY AND RISK SIMULATIONS OF BIODIESEL PRODUCTION THROUGH SOYBEAN WASTE}

\section{ABSTRACT}

The present study aims to analyze the financial viability, complemented by simulations of risk of the implementation and operation of a biodiesel producing plant from soybean residues of the Port of Paranaguá, in order to supply part of the demand for fuels and consequently reduce waste and problems caused by inappropriate disposal of this oilseed. The financial analysis was accomplished by the traditional method of evaluation of investments and, for the risk analysis, was used the Monte Carlo's simulation technique. The minimum attractiveness rate (MAR) considered in the studied case was of $7.25 \%$. From the financial analysis, the following data were obtained: payback in the 5 th year, liquid present value (LPV) of $\mathrm{R} \$ 1.089 .537,56$ and rate of internal return (RIR) of $27 \%$ per year. The result of the simulations indicated for the output variable (LPV) a medium value of $R \$$ 296.303,13. As a final result, the simulation shows that there would be $18,8 \%$ chance that the investment would not provide the minimum return expected by the entrepreneur, depending on the situation adopted. As result, the process of simulation techniques in the generation of information has extreme importance for taking decisions.

KEYWORDS: Financial Viability; Risk Simulations; Port of Paranaguá; Soybean Waste; Biodiesel.
Revista Brasileira de

Administração Científica,

Aquidabã, v.6, n.1, Jan, Fev, Mar, Abr, Mai, Jun 2014.

ISSN 2179-684X

SECTION: Articles

TOPIC: Finanças e Contabilidade

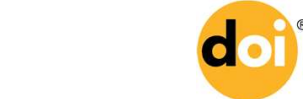

DOI: 10.6008/SPC2179-684X.2015.001.0005

\begin{abstract}
Humberto Santiago Pazzini Universidade Federal Fluminense, Brasil http://lattes.cnpq.br/6796180226675212

humpazzini@yahoo.com.br
\end{abstract}

Aurélio Lamare Soares Murta Universidade Federal Fluminense, Brasil http://lattes.cnpq.br/7344029160665638

aureliomurta@yahoo.com.br

Cristina Kurtz Motta

Universidade Federal Fluminense, Brasil http://lattes.cnpq.br/5866819848078002 cristinakm@gmail.com

Danyelle Stringari

Universidade Estadual do Paraná, Brasil http://lattes.cnpq.br/6235127981805861 danystringari@gmail.com

Received: 06/10/2014

Approved: 14/10/2015

Reviewed anonymously in the process of blind peer.

Referencing this:

PAZZINI, H. S.; MURTA, A. L. S.; MOTTA, C. K.; STRINGARI, D.. Viabilidade econômica e simulação de monte carlo da produção de biodiesel de resíduos de soja. Revista Brasileira de Administração Científica Aquidabã, v.6, n.1, p.76-91, 2015. DOI: http://dx.doi.org/10.6008/SPC2179. $\underline{684 X .2015 .001 .0005}$ 


\section{INTRODUÇÃO}

A dependência mundial em relação à indústria do petróleo, as mudanças climáticas, que resultam no aquecimento global e aumento dos níveis dos oceanos, dentre outras consequências, têm suscitado uma crescente necessidade de desenvolver novas formas de energia, limpas, renováveis e de menor impacto. Uma alternativa possível à redução do uso do petróleo, de acordo com a American Soybean Association (2013), é a utilização de óleos de origem vegetal, os quais podem ser denominados de biodiesel.

A maior parte do biodiesel atualmente produzido no mundo deriva da soja, que é o principal grão produzido no país e o mais importante item de exportação brasileira, apresentando grande participação no Produto Interno Bruto (PIB). Segundo dados da Companhia Nacional de Abastecimento (Conab), (2014), em 2013, o complexo soja (que abrange o grão de soja e seus subprodutos, como: farelo e óleo), obteve uma participação de $32,4 \%$ do agronegócio nacional e no total das exportações, de 13,7\% (CONAB, 2014).

Nesse contexto, o Porto de Paranaguá, localizado no Estado do Paraná, figura como um dos maiores exportadores de soja e, por conseguinte, maiores geradores de resíduos. Atualmente, esses resíduos têm causado poluição ambiental e proliferação da fauna sinantrópica nociva, além de contribuir na disseminação de doenças na área do município que abriga o porto. Tendo em vista o volume significativo de resíduos de soja descartados de forma subaproveitada, bem como a tecnologia existente e os impactos causados no porto, o presente trabalho tem por finalidade analisar a viabilidade da implantação e operação de uma usina produtora de biodiesel de resíduos de soja no Porto de Paranaguá.

Ressalta-se que o lançamento de um empreendimento desse vulto, dada à exclusividade, é uma decisão de grande impacto para a empresa e, consequentemente, repleta de riscos e incertezas, visto que geralmente há longo período entre os investimentos e a total absorção do produto pelo mercado. Nesse sentido, para proporcionar mais segurança na tomada de decisão e garantir maior assertividade na seleção das oportunidades de investimentos, realizou-se uma análise de viabilidade financeira, complementada por simulações de risco, tomando como referência um projeto de produção de biodiesel.

\section{REVISÃO TEÓRICA}

Nesta seção de revisão serão abordados os métodos de avaliação financeira (VPL, PAYBACK e TIR), os de simulação de risco (Método Monte Carlo) e a produção de biodiesel, bem como as fontes de matéria-prima, destacando o papel desse biocombustível para a economia e para a mitigação de impactos socioambientais. 


\section{Análise Determinística}

Segundo Assaf Neto (2003), as avaliações de empreendimentos dependem, sobremaneira, das expectativas futuras de desempenho. Desta forma, a viabilidade de um projeto passa pela decisão de investimento (aplicação de recursos) e decisão de financiamento (captação de recursos). Assim, a avaliação do empreendimento proposto foi realizada com o objetivo de verificar se a renda gerada pela usina de biodiesel remunera ou não o capital investido. Os métodos de avaliação empregadas: período de payback; valor presente líquido (VLP) e taxa interna de retorno (TIR). Método do prazo de recuperação de capital (payback). O período de payback é exatamente o tempo necessário para o investidor recuperar seu investimento inicial em um projeto. Além disso, é um método auxiliar utilizado como indicador do grau de risco do projeto. Cabe ressaltar que quanto mais curto o período de payback, maior será a liquidez do projeto (GITMAN, 2010).

Valor presente líquido (VPL). O VPL dos fluxos de caixa de um investimento é encontrado ao se subtrair o investimento inicial de um projeto, do valor presente de seus fluxos de entradas de caixa, descontados a uma taxa de retorno ou custo de oportunidade. É uma medida do rendimento líquido esperado do investimento realizado ou em perspectiva, expresso em moeda corrente atual. Essa técnica apresenta o seguinte critério para tomada de decisão: se o VPL encontrado for negativo, rejeita-se o projeto, caso contrário ele é aceito (GASLENE et al., 1999).

Método da taxa interna de retorno (TIR). A TIR, ou simplesmente 'taxa interna', é a taxa de desconto que iguala o valor presente de fluxos de entrada de caixa com o investimento inicial associado a um projeto, tornando o valor presente líquido de um investimento igual a zero. A análise da TIR dos investimentos de interesse da empresa permite a tomada de decisão acerca de uma série de questões, como, por exemplo, comparar e decidir entre distintas oportunidades de investimentos realizados. De maneira prática, se a TIR é maior do que o custo de capital, devese aceitar o projeto, caso contrário se rejeita (HOJI, 2006).

\section{Simulação de Monte Carlo}

Para complementar a análise determinística do caso em tela e avaliar o risco de investir na produção de biodiesel, foram realizados três simulações pelo Método de Monte Carlo (MMC). O MMC é uma abordagem comportamental baseada em estatística, que, em cenários contingenciais, se torna uma alternativa para obtenção do retorno esperado e do risco de um projeto, através de simulação (GITMAN, 2010).

Barbosa (2000) define o MMC como "a técnica de simulação que envolve a utilização de números aleatórios e distribuição estocástica de probabilidade" (BARBOSA, 2000, p.2). De acordo com Sandroni (1998), um modelo estocástico é aquele que contém pelo menos um elemento aleatório, gerando um resultado probabilístico. Para Costa e Azevedo (1996), nesta ferramenta 
são geradas várias simulações, que se referem a um amplo conjunto de métodos e aplicações para imitar o comportamento de um sistema real.

Em estudos de viabilidade, são comuns as entradas e saídas serem consideradas conhecidas. A despeito da sua funcionalidade, essa medida leva à simplificação e/ou à super estimativa de informações que nem sempre são conhecidas com certeza no período da análise, como custos, quantidades, preços, entre outros. Para a mitigação dessa possível distorção de informações, foi adotada uma análise probabilística que possibilite incorporar os riscos normalmente associados aos projetos de empreendimentos. Assim, a fim de tornar possível a implementação dessa análise, foram avaliados os dados mediante a utilização do MMC em planilhas eletrônicas do software Microsoft Office Excel (2010), dispensando a utilização de software específicos de simulação. Esse programa auxilia nos cálculos e na análise, permitindo a aplicação do MMC e garantindo às variáveis aleatórias a independência, a aleatoriedade e a não repetição de sequências.

\section{A Produção de Biodiesel: A Contribuição da Soja e de Outras Oleaginosas}

O biodiesel é um biocombustível renovável, limpo e biodegradável, obtido através do craqueamento, esterificação ou transesterificação (Associação Brasileira das Indústrias de Óleos Vegetais, 2012). De acordo com Agencia Nacional do Petróleo (2012) o biodiesel é um substituto natural do diesel de petróleo e pode ser produzido a partir de fontes renováveis, como óleos vegetais, gorduras animais e gordura residual (fritura de alimentos), com destaque para a utilização da soja, com $83 \%$ do total.

Contudo, a cadeia produtiva bem estruturada, as opções de conversibilidade da oleaginosa e a maneira como está estruturado o seu complexo, colocam o biodiesel de soja como uma alternativa a ser fortemente considerada (Ministério da Agricultura, Pecuária e Abastecimento, 2009). A transesterificação, intensamente utilizada na produção do biodiesel nacional, consiste numa reação química da matéria-prima com etanol ou metanol, sendo estimulada por um catalisador, resultando em biodiesel e glicerina (PARENTE, 2003). Esse método será adotado no presente estudo de viabilização de implantação da usina de biodiesel no Porto de Paranaguá.

Segundo Ferrari et al. (2005), a produção de biodiesel, desde o processamento da matériaprima até a obtenção do produto final, é constituída, basicamente, pela extração de óleo (esmagamento), seguida pela produção de biodiesel propriamente dita, descrita neste artigo como transesterificação por rota metílica, que tem o objetivo de extrair o óleo contido no interior das oleaginosas. Desta etapa ainda resulta a torta, que pode ser comercializada, dependendo do processamento, como ração animal ou fertilizante. Na reação de transesterificação, o óleo obtido da etapa anterior soma-se a outros insumos e finalmente resulta em biodiesel e glicerina. 


\section{METODOLOGIA}

Baseando-se em toda a discussão levantada, pretende-se demonstrar o modelo desenvolvido para apurar os custos de produção de biodiesel. Para tal, foi descrita a planta do complexo de biodiesel, composta pela unidade de esmagamento (extração de óleo dos resíduos de soja) e pela usina propriamente dita (transformação do óleo em biodiesel), bem como as ferramentas de avaliação do investimento. Embora a usina seja um empreendimento ambientalmente responsável, só é possível cumprir a função social se for capaz de apresentar resultados que garantam o retorno satisfatório do capital investido. Portanto, para decidir sobre a viabilidade e risco deste projeto, foram utilizados os recursos período de payback, o valor VPL) e a TIR), complementadas pelo MMC.

\section{Delimitação do Estudo}

O projeto da usina de produção de biodiesel, a partir de resíduos de soja, baseou-se em um estudo de viabilidade com a unidade de análise constituída pelo Porto de Paranaguá, situado no município homônimo, no Estado do Paraná. Os critérios adotados na seleção desta unidade de produção de biodiesel foram: a relevância quanto ao volume e valores monetários movimentados de produtos agrícolas, especialmente a soja; e a sua expressiva geração de resíduos, a qual favorece a implantação da usina. Apesar do resíduo de soja ser gerado em distintos pontos do porto e do seu entorno, para a análise de viabilidade foram considerados apenas os resíduos gerados no Corredor de Exportação (COREX), cujos dados (área do COREX, quantidades e tipos de resíduos) foram aferidos com relatórios emitidos pela Autoridade Portuária de Paranaguá e Antonina - APPA (2012). A área pode ser vista em detalhes na Figura 1.

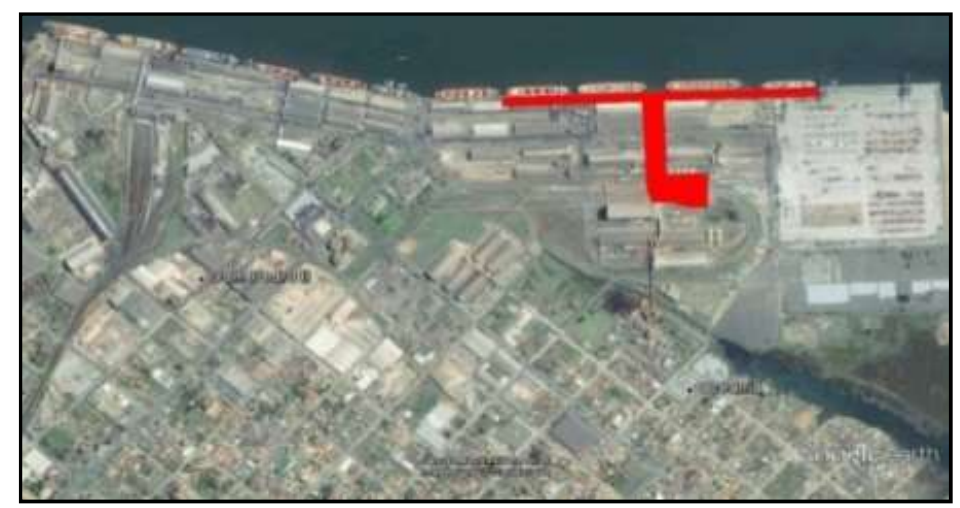

Figura 1: Corredor de exportação.

Fonte: APPA (2012)

Os $55.650 \mathrm{~m}^{2}$ do COREX, foco da análise neste estudo, são formados por onze terminais portuários, entre públicos, privados e arrendados, todos interligados, representando $2,4 \%$ da área porto organizado $\left(2.350 .000 \mathrm{~m}^{2}\right)$ e gerando $85 \%$ do total de resíduos do Porto de Paranaguá, conforme relatório emitido pela Administração dos Portos de Paranaguá e Antonina (APPA, 2012). 
O presente estudo de viabilidade contabilizou 5.717 toneladas de resíduos de cereais (milho, trigo e soja), açúcar e fertilizantes geradas no porto em 2011. Do total, 4.856 toneladas (85\%) foram geradas no COREX, o que justifica a eleição desta área para o presente estudo (SEBRAE, 2012, AOCEP, 2012). Outra razão para a delimitação do tema foi a evidência de que os resíduos de soja descartados no COREX são mais limpos e melhor tratados do que os resíduos de outras áreas do Porto.

\section{Descrição do Processo de Extração de Óleos e Produção de Biodiesel}

O projeto da usina de produção de biodiesel do Porto de Paranaguá abrangerá, basicamente, duas grandes unidades, que são: Unidade esmagadora: nesta unidade será realizada a extração mecânica do óleo vegetal contido nos grãos de soja sem a adição de solvente, bem como a separação da torta, que consiste na mistura de óleo e oleaginosa, oriunda do processo mecânico de esmagamento (prensa) de uma oleaginosa qualquer, que após alguns tratamentos é transformada em farelo ou fertilizantes. A torta de soja poderá ser vendida em outros mercados. Salienta-se que, em condições normais, ou seja, extração de óleo de grãos de soja e não de resíduos, o processo de beneficiamento da torta/farelo gera fertilizante e/ou ração animal como subprodutos. No entanto, como a Agência Nacional de Vigilância Sanitária (ANVISA) proíbe a utilização de resíduos de soja despejados no solo para consumo humano ou animal, toda a produção do subproduto foi direcionada para a comercialização de fertilizantes; Unidade de produção de biodiesel, a partir do processo de transesterificação do óleo de soja: esta unidade será composta pela unidade de produção de biodiesel propriamente dita, além da sede administrativa, laboratório de análises químicas, sistema de armazenagem de produtos e demais componentes. Serão realizadas na unidade as atividades gerenciais, a recepção dos insumos necessários ao processo produtivo, como óleo, álcool, catalisador e aditivos químicos, além do controle de qualidade de matéria-prima e do produto final (glicerina e biodiesel) por meio das análises laboratoriais.

\section{Considerações Tecnológicas}

O método envolveu a transesterificação do óleo de soja (oriundo dos resíduos), utilizando como agente transesterificante o metanol em condições básicas, com o $\mathrm{KOH}$ (hidróxido de potássio). Para Meher et al. (2004), a adição de um catalisador (ácido ou base) acelera significativamente a reação de transesterificação, ao qual originará o éster, que após devidamente tratado, conforme as normas da Agência Nacional de Petróleo (ANP) (AGÊNCIA, 2012), poderá ser utilizado como biodiesel. Em síntese, a reação de transesterificação, detalhada na Figura 2, consiste numa etapa de conversão, neste caso óleo de soja em biodiesel. 


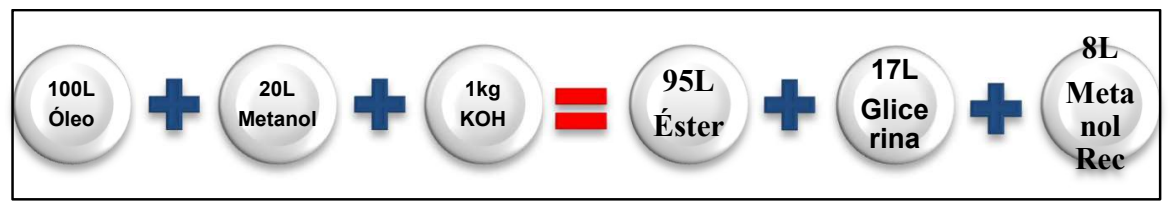

Figura 2: Reação de transesterificação.

Fonte: MURTA (2008).

Nesta figura, síntese da produção de biodiesel deste estudo de viabilidade, foi considerada a mesma proporção utilizada no trabalho de Murta (2008). A transesterificação abordada consiste em uma reação química de óleo de soja com o álcool (metanol), estimulada por um catalisador, nesse caso, hidróxido de potássio $(\mathrm{KOH})$. Deste processo também é possível extrair o subproduto glicerina, empregado para fabricação de sabonetes e diversos outros cosméticos. Outro input considerável é o metanol residual, que provém da separação inadequada durante o processo de purificação do biodiesel.

\section{Análise Determinística}

Os métodos utilizados neste trabalho foram o payback; o Valor Presente Líquido (VPL) e a Taxa Interna de Retorno (TIR). Depois de calculado o custo final do biodiesel (B100), comparouse com o preço médio do diesel de Paranaguá do ano 2013, com o preço médio do biodiesel (29 leilão da ANP), bem como se aferiu o custo da mistura (B20). Para calcular o custo do biodiesel, salienta-se que foi tomado como base o valor de $\mathrm{R} \$ 150.679,17$, que corresponde ao custo da saca de soja em Paranaguá (de abril de 2013), multiplicado por $140.700 \mathrm{~kg}$ de resíduos de soja, equivalente a quantidade mensal de resíduos gerados no Porto de Paranaguá. Baseado no valor de $\mathrm{R} \$ 150.679,17$ foram propostos três cenários: Aquisição dos resíduos de soja por $20 \%$ ou do valor de mercado da soja ou $\mathrm{R} \$ 30.123,84$ (cenário mais provável); Obtenção gratuita dos resíduos de soja (cenário otimista) e Aquisição dos resíduos de soja por $50 \%$ do valor de mercado ou $\mathrm{R} \$ 75.339,58$ (cenário pessimista).

No entanto, para os cálculos das ferramentas payback, TIR e VPL, foram considerados apenas o cenário mais provável, pois a simulação de Monte Carlo é uma ferramenta que cria vários cenários possíveis, e não somente aqueles três usuais cenários determinísticos apontados: otimista, pessimista e mais provável. Para a análise determinística e para a simulação de Monte Carlo, que será estudada a seguir, o projeto a ser implantado terá vida útil de 10 anos, tempo da sua total depreciação. O custo de capital, utilizado nos cálculos da análise determinística e da simulação, foi considerado como sendo a taxa do Sistema Especial de Liquidação e Custódia (SELIC), divulgada pelo Comitê de Política Monetária (COPOM) do Banco Central, pois as taxas de juros cobradas pelo mercado são baseadas na mesma. A taxa SELIC do dia 6 de março de 2013 foi fixada em 7,25\% ao ano e utilizada nos cálculos como o custo de capital (BACEN, 2013). 


\section{Simulação pelo Método de Monte Carlos}

Para complementar a análise determinística e avaliar o risco de investimento na produção de biodiesel a partir dos resíduos de soja, foram realizados simulações pelo Método de Monte Carlo. No presente trabalho, a função 'Aleatória' do Excel, entendida como uma distribuição uniforme contínua que o programa gera, foi utilizada tanto para o cálculo do preço de mercado do biodiesel quanto para o cálculo do custo da matéria-prima (resíduos de soja). O MMC permite simular valores para as variáveis independentes e, em consequência dos valores aleatórios gerados, obter valores para a variável dependente. No estudo, enquanto o preço de mercado do biodiesel e o custo de aquisição dos resíduos de soja foram considerados como variáveis independentes (inputs), o VPL e TIR foram determinados como dependentes (outputs).

Para analisar o risco, o menor e maior custo de resíduos inseridos na simulação foi de $\mathrm{R} \$$ 0,00 a $R \$ 50.226,39$, isto é, o custo de aquisição variou de $R \$ 0,00$ (gratuito) a um terço do preço da soja, respectivamente. Recorda-se que o maior e o menor custo de resíduos de soja (inputs da simulação) foram calculados levando em consideração a mesma base da análise determinística de $R \$ 150.679,17$. Outra consideração importante se refere ao preço de mercado do biodiesel, um dos inputs da simulação, que nos três cenários variou de $R$ \$ 1,90/L a $R$ \$ 2,50/L (variação aproximada de todos os leilões realizados pela ANP). A fim de garantir a qualidade dos resultados, foram feitas 1.000 iterações, consideradas como variáveis. Para gerar o conjunto de dados iniciais das variáveis independentes, foram realizados estudos na região em análise, adicionando à matriz de inputs apenas dados autênticos, fundamentados em usinas e construções com perfis semelhantes ao do empreendimento em questão.

\section{RESULTADOS}

Nesta seção será apresentado um estudo de viabilidade econômico-financeira de uma usina de biodiesel, o qual foi obtido a partir de resíduos de soja provenientes do Porto de Paranaguá. A seção expõe e discute os dados coletados e os resultados alcançados durante a pesquisa.

\section{Demanda por Óleo Vegetal, Área Produtiva Necessária e Produção de Biodiesel}

COREX gera aproximadamente 1.682 toneladas ao ano (140,7 t/mês) de resíduos de soja, conforme já demonstrado. Desta maneira, a unidade de extração de óleo (esmagadora) deverá atender a demanda de grãos, obtendo óleo de soja degomado, produto resultante do esmagamento (prensa) da soja, que, por sua vez, produzirá 387.600 litros de biodiesel por ano (1.292 l/mês). A Tabela 1 inclui informação quantitativa da produção de biodiesel de óleo de soja. Os cenários propostos - mais provável, otimista e pessimista - foram definidos com base nos 
dados obtidos por Murta (2008).

Tabela 1: Produção de biodiesel de óleo de soja.

\begin{tabular}{lllll}
\hline Soja & Unidade & Mais Provável & Otimista & Pessimista \\
\hline Custo de Óleo & $\mathrm{R} \$ / \mathrm{L}$ & 1,021 & 0,1581 & 2,3146 \\
\hline Soja em Grãos & $\%$ & $20 \%$ & $0 \%$ & $50 \%$ \\
\hline Rendimento (Óleo) & $\%$ & 0,18 & 0,18 & 0,18 \\
\hline Produtividade de Grãos & $\mathrm{t} / \mathrm{ha}$ & 2,5 & 2,5 & 2,5 \\
\hline Produtividade de Óleo & $\mathrm{t} / \mathrm{ha}$ & 0,45 & 0,45 & 0,45 \\
\hline Densidade Óleo de Soja & $\mathrm{kg} / \mathrm{L}$ & 0,92 & 0,92 & 0,92 \\
\hline Produtividade de Óleo & $\mathrm{L} / \mathrm{ha}$ & 414,9 & 414,9 & 414,9 \\
\hline Quantidade Recolhida de Grãos & $\mathrm{t} / \mathrm{mês}$ & 140,17 & 140,17 & 140,17 \\
\hline Quantidade Recolhida de Grãos & t/ano & 1.682 & 1.682 & 1.682 \\
\hline Área Colhida Necessária & ha/ano & 672,8 & 672,8 & 672,8 \\
\hline
\end{tabular}

\section{Complexo de Produção de Biodiesel}

O complexo de produção de biodiesel do Porto de Paranaguá é constituído basicamente por duas unidades principais, denominadas Unidades de Extração de Óleo (Esmagamento) e Unidade de Produção de Biodiesel.

\section{Custos de Implantação da Usina}

Os recursos necessários à implantação do complexo para a produção de biodiesel e atendimento à utilização dos resíduos de soja totalizarão $R \$ 1.106 .573,56$. Tais recursos foram divididos em edificações, equipamentos e sistema de armazenagem. Enquanto as edificações, representadas por galpão, sede administrativa e laboratório totalizaram $274 \mathrm{~m}^{2}$, tendo um valor aproximado de $\mathrm{R} \$ 245$ mil; os equipamentos totalizaram investimentos aproximados de $\mathrm{R} \$ 770$ mil. Já o sistema de armazenagem, composto por tanques e silos, que permitirão a armazenagem de biodiesel, glicerol, insumos (metanol, catalisador, aditivos, água e óleo) consumiu cerca de R\$ 91,7 mil.

\section{Insumos Necessários ao Processo Produtivo}

A capacidade máxima nominal da máquina de processamento de biodiesel é de 408.000 mil litros. Contudo, o complexo proposto produzirá 387.600 mil litros de biodiesel anuais. Esta diferença decorre naturalmente da produção de biodiesel no qual são gerados subprodutos como glicerol e metanol, em excesso, água de lavagem (purificação) e resíduos. Todo o volume processado é composto por óleo, metanol, $\mathrm{KOH}$, água de processo e energia elétrica. Os valores referentes às necessidades diárias, mensais e anuais dos insumos estão sintetizados na Tabela 2.

Tabela 2: Insumos necessários ao processo industrial.

\begin{tabular}{lllll}
\hline Usina & Unidade & Diária & Mensal & Anual \\
\hline Processamento Nominal Projetado & L & 1.360 & 34.000 & 408.000 \\
\hline Produção final de Biodiesel & L & 1.292 & 32.300 \\
\hline Rendimento Glicerol & L & 193 & 387.600 \\
\hline
\end{tabular}




\begin{tabular}{|c|c|c|c|c|}
\hline Consumo de energia geral (380v) & $\mathrm{kWh}$ & 694 & 17.349 & 208.192 \\
\hline Consumo de água geral & $\mathrm{L}$ & 204 & 5.100 & 61.200 \\
\hline Demanda Óleo & $\mathrm{L}$ & 1.124 & 28.099 & 337.190 \\
\hline Demanda Metanol & $\mathrm{L}$ & 163 & 4.080 & 48.960 \\
\hline Demanda de $\mathrm{KOH}$ & $\mathrm{Kg}$ & 14 & 340 & 4.080 \\
\hline Demanda Aditivos Químicos & $\mathrm{L}$ & 5 & 129 & 1.550 \\
\hline
\end{tabular}

\section{Resumo dos Custos Operacionais}

Tomando-se por base a produção do biodiesel e apoiada nas necessidades de insumo da Tabela 2, foram aferidos os custos para a operação do complexo. Salienta-se que a matériaprima, constituída por óleo, metanol, $\mathrm{KOH}$, aditivos e água, representa $56,4 \%$ do total de custos. Isto denota que a obtenção do biodiesel é muito intensiva no quesito matérias-primas, tornando relevante o preço de aquisição destas no mercado. Os custos operacionais da produção do biodiesel de soja estão sintetizados na Tabela 3.

Tabela 3: Resumo dos custos operacionais.

\begin{tabular}{lllll}
\hline Resumo dos Custos Operacionais & Mês & Dia & Litro & $\%$ \\
\hline Matéria Prima & $33.943,10$ & $1.357,724$ & 1,0509 & $56,8 \%$ \\
\hline Transformação & $8.709,02$ & 348,36 & 0,270 & $14,6 \%$ \\
\hline Impostos & $9.727,37$ & 389,09 & 0,301 & $16,3 \%$ \\
\hline Salários & $7.348,44$ & 293,94 & 0,228 & $12,3 \%$ \\
\hline Total & $59.727,94$ & $2.389,12$ & 1,849 & $100 \%$ \\
\hline
\end{tabular}

A Tabela 3 demonstra que a produção é pouco intensiva em mão de obra, dentre outros motivos, porque as usinas de biodiesel são geralmente automatizadas, e o projeto é de pequeno porte. Nesta categoria, ainda serão computados aprovisionamentos trabalhistas mensais, como décimo terceiro salário e férias. Nessa estrutura ainda observa-se um relativo equilíbrio nos custos de impostos, salários e transformação, o qual é composto por necessidades energéticas, custos de gerenciamento e manutenção. Outro custo a destacar são os impostos, compostos por licenças e tributos referentes à instalação e operação do complexo. Convém ressaltar que o custo de transporte não aparece neste resumo porque foi incluso integralmente no custo do óleo.

\section{Custos de Produção de Biodiesel}

Para calcular todos os custos da usina de biodiesel, o presente trabalho considerou os seguintes custos: custo fixo, custo variável, custo total e custo médio (Tabela 4). Este último é encontrado pela divisão do custo total pela quantidade produzida, podendo ser compreendido também como o custo unitário de produção. É bastante utilizado para a comparação de preço de venda, já que para um determinado nível de produção representa os custos de cada unidade produzida. Neste caso, os três custos médios do biodiesel produzido no complexo resultarão da divisão dos custos totais de cada cenário pela produção mensal de biodiesel (32.300 litros). A partir dos cálculos realizados para o empreendimento, apurou-se que o custo final de transformação de 1 litro de óleo vegetal em 1 litro de biodiesel terá um valor médio com impostos 
equivalente a $R \$ 0,83, R \$ 0,94$ e $R \$ 0,66$ para os cenários mais provável, otimista e pessimista, respectivamente observados na Tabela 4.

Ainda com base nos dados descritos na Tabela 4, foi possível chegar ao preço final do biodiesel produzido no Porto de Paranaguá. Desta maneira, o custo final por litro de biodiesel produzido terá os valores de $\mathrm{R} \$ 1,85$ para o cenário mais provável, $\mathrm{R} \$ 1,10$ para o cenário otimista e $\mathrm{R} \$ 2,97$ para o cenário pessimista. Para efeitos de análise, foram calculados os custos do biodiesel produzido na usina de resíduos e comparado com o preço do biodiesel e diesel comercializados em Paranaguá (Tabela 5). Os custos finais do biodiesel gerado na usina (B100), tanto do cenário mais provável como do otimista, são inferiores ao valor médio do diesel, que em Paranaguá é de $R \$ 2,22$, bem como os $R \$ 2,24$ do biodiesel do mercado (Tabela 5).

Salienta-se que, no cenário otimista ao custo do biodiesel da usina é de $R \$ 1,10$, o que equivale a aproximadamente metade do preço médio do biodiesel $(R \$ 2,24)$ e do diesel $(R \$ 2,22)$. Já o custo do cenário pessimista fica superior ao preço do diesel e do biodiesel, conforme demonstrado na Tabela 5, o que torna a produção inviável, se analisada apenas sob o ponto de vista econômico. Essa distorção entre os custos de produção do biodiesel é explicada pela diferença significativa entre os custos de óleo degomado, observado nos três cenários.

Cabe informar que o custo final do biodiesel produzido na usina de resíduos pelo porto foi calculado no presente trabalho - incluindo o óleo degomado, principal matéria-prima da usina proposta no Porto de Paranaguá, bem como o biodiesel produzido oriundo dos resíduos. O montante de $\mathrm{R} \$ 2,24$ (Biodiesel mercado) equivale ao preço médio do biodiesel comercializado no $29^{\circ}$ leilão da ANP. Os R\$ 2,22 (Diesel Mercado) correspondem ao preço médio do diesel comercializado em Paranaguá. O custo do óleo de $R \$ 2,31$, aferido no cenário pessimista, por si só inviabiliza a produção de biodiesel na usina, já que seu valor é superior ao custo do biodiesel e do diesel encontrados no mercado. Isso denota o impacto significativo do óleo no custo de produção.

Tabela 4: Custos fixos, variáveis e total.

\begin{tabular}{|c|c|c|c|}
\hline Resumo dos custos (mensais) & Mais provável & Otimista & Pessimista \\
\hline \multicolumn{4}{|l|}{1 - Custos Fixos } \\
\hline Tributos & $2.117,00$ & $2.117,00$ & $2.117,00$ \\
\hline Gerenciamentos & $2.260,00$ & $2.260,00$ & $2.260,00$ \\
\hline Manutenções & $1.700,00$ & $1.700,00$ & $1.700,00$ \\
\hline Salários & $5.800,00$ & $5.800,00$ & $5.800,00$ \\
\hline Provisionamentos & $1.548,44$ & $1.548,44$ & $1.548,44$ \\
\hline Subtotal & $13.425,44$ & $13.425,44$ & $13.425,44$ \\
\hline \multicolumn{4}{|l|}{2 - Custos Variáveis } \\
\hline Tributos & $7.610,37$ & $7.610,37$ & $7.610,37$ \\
\hline Custo Óleo & $28.681,54$ & $4.443,56$ & $65.038,52$ \\
\hline Custo Metanol & $4.252,44$ & $4.252,44$ & $4.252,44$ \\
\hline Custo $\mathrm{KOH}$ & 519,52 & 519,52 & 519,52 \\
\hline Custo Aditivos & 387,60 & 387,60 & 387,60 \\
\hline Custo Água & 102,00 & 102,00 & 102,00 \\
\hline Custo Energia & $4.749,02$ & $4.749,02$ & $4.749,02$ \\
\hline Subtotal & $46.302,50$ & $22.064,52$ & $82.659,47$ \\
\hline Custo Total & $59.727,94$ & $35.489,96$ & $96.084,92$ \\
\hline Custo Unitário s/ Impostos & 1,55 & 0,80 & 2,67 \\
\hline Custo Unitário c/ Impostos & 1,85 & 1,10 & 2,97 \\
\hline Impostos & 0,30 & 0,30 & 0,30 \\
\hline Preço de Venda & 2,24 & 2,24 & 2,24 \\
\hline Custo Transformação s/lmpostos & 0,53 & 0,64 & 0,36 \\
\hline
\end{tabular}


Nota: valores expressos em reais.

Tabela 5: Matriz valores de biodiesel e diesel.

\begin{tabular}{lllll}
\hline Cenários & Óleo degomado & Biodiesel usina & Biodiesel mercado & Diesel mercado \\
\hline Mais provável & 1,02 & 1,85 & 2,24 & 2,22 \\
\hline Otimista & 0,16 & 1,10 & 2,24 & 2,22 \\
\hline Pessimista & 2,31 & 2,97 & 2,24 & 2,22 \\
\hline
\end{tabular}

Nota: valores expressos em reais.

\section{Análise Econômico-Financeira e Simulação de Risco}

Enquanto na análise econômica financeira (determinística) foram abordadas as ferramentas clássicas de investimento, como período de payback, VPL e TIR, na análise de risco primou-se pela Simulação Método Monte Carlo (MMC).

\section{Análise Determinística}

$\mathrm{Na}$ abordagem determinística do payback, do VPL e da TIR, foram analisados apenas os valores do cenário mais provável, que considera o custo de aquisição dos resíduos como sendo $20 \%$ do preço de mercado da soja. A partir deste valor, apuraram-se os custos, receitas e fluxo de caixa, dentre outros. Os outros cenários foram utilizados apenas na análise do subtítulo denominado "custos de produção de biodiesel". Após a montagem do fluxo de caixa e realização dos cálculos, foram apurados os seguintes resultados, conforme Tabela 6.

Tabela 6: Resultados da análise econômica.

\begin{tabular}{ll}
\hline Parâmetro considerado & Resultado obtido \\
\hline Valor presente líquido do complexo & $\mathrm{R} \$ 9.211 .370,16$ \\
\hline Taxa interna de retorno & $14 \%$ \\
\hline Tempo de retorno & $13^{\circ}$ ano \\
\hline
\end{tabular}

Observando-se apenas os valores da Tabela 6, pode-se concluir, sob o ponto de vista econômico, que a implantação do empreendimento é viável, uma vez que foram consideradas as seguintes premissas e seus comentários. Primeiramente, analisou-se o tempo de recuperação do capital da usina de produção de biodiesel. O payback dá-se no $5^{\circ}$ ano, quando o fluxo acumulado registra o valor positivo de $R \$ 212.560,28$. O valor presente líquido (VPL) do projeto é de $R \$$ 1.089.458,91. Esse valor positivo significa que os gastos com a execução do projeto remuneram o investidor em $7,25 \%$ ao ano (TMA) e ainda permitem aumentar o valor da empresa em uma quantia igual ao VPL, demonstrando, assim, ser financeiramente viável. O projeto da usina apresenta taxa interna de retorno (TIR) de $27 \%$ ao ano, indicando boa rentabilidade do capital investido nesse projeto (Tabela 6).

\section{Análise de Risco: Simulação de Monte Carlo}

Para aferir o risco do projeto, o custo mínimo de aquisição dos resíduos de soja 
considerado foi de $R \$ 0,00$, e o máximo de $R \$ 50.226,39$, isto é, variou de $0 \%$ (gratuito) a $1 / 3$ do valor básico de $\mathrm{R} \$ 150.679,17$, respectivamente. Além disso, foi considerada uma vida útil do projeto de 10 anos. Como resultado das simulações de Monte Carlo (Tabela 7), as variáveis de saída (VPL) apresentaram valores médios de $\mathrm{R} \$ 1.247 .215,44$ e desvio-padrão de $\mathrm{R} \$$ 1.208.142,98.

Tabela 7: Valores máximos, mínimos e médios do VPL.

Valor Presente Líquido (VPL) do Complexo - Resultado da Simulação

\begin{tabular}{llll}
\hline Mínimo & Média & Máximo & Desvio-Padrão \\
\hline $\mathbf{- 1 . 3 7 2 . 4 1 3 , 2 2}$ & $1.247 .215,44$ & $3.889 .110,12$ & $1.208 .142,98$ \\
\hline
\end{tabular}

Nota: valores expressos em reais.

E a análise dos percentis indicou uma probabilidade de $10 \%$ de o VPL apresentar o valor inferior a - $\mathrm{R} \$ 394.365,50$, e $90 \%$ de probabilidade de exibir valor (mínimo) superior a $\mathrm{R} \$$ 2.873.533,38 (Tabela 8).

Tabela 8: Análise descritiva das variáveis de resultado do complexo.

\begin{tabular}{ll}
\hline Percentis & Probabilidades \\
\hline$-R \$ 394.365,50$ & $10 \%$ \\
\hline$R \$ 492.308,72$ & $30 \%$ \\
\hline$R \$ 1.252 .828,91$ & $50 \%$ \\
\hline$R \$ 2.005 .387,90$ & $70 \%$ \\
\hline$R \$ 2.873 .533,38$ & $90 \%$ \\
\hline
\end{tabular}

As probabilidades dos resultados do Valor Presente Líquido (VPL) podem ser observadas no gráfico presente na Gráfico 1, o qual demonstra a probabilidade de 18,8\% do investimento não oferecer o retorno mínimo desejado, expresso pela TMA de 7,25 a.a.

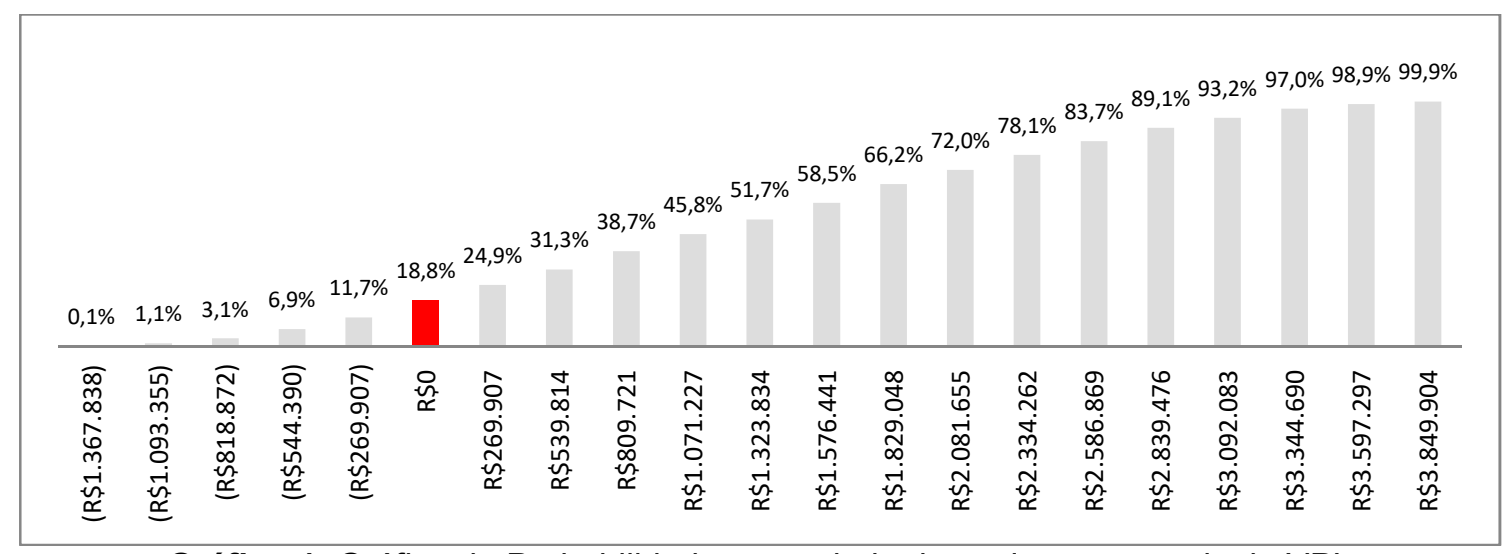

Gráfico 1: Gráfico da Probabilidade acumulada dos valores em reais do VPL

As 1000 iterações da simulação, conforme já exposto, delineiam a viabilidade financeira do investimento mesmo em condições de risco e incerteza, apresentando as vantagens de se considerar, na análise de avaliação financeira de investimentos, o elemento de risco através da construção de cenários e da simulação de variações exógenas, componentes bem discutidos neste estudo. 


\section{CONCLUSÕES}

Este estudo valeu-se da análise de viabilidade financeira, complementada por simulações de risco, em um projeto de implantação e operação de uma usina de biodiesel de resíduos de soja no Porto de Paranaguá, como instrumento estatístico para suprir os investidores de informações mais condizentes com a realidade. Destaca-se que a utilização do MMC possibilita a criação de vários cenários, e não somente aqueles três usuais cenários determinísticos: otimista, pessimista e mais provável. A simulação pode fornecer decisões mais seguras diante da análise de risco e de cenários em detrimento da simples análise determinística.

A variável de grande sensibilidade e que poderá comprometer a viabilidade do empreendimento é o preço dos resíduos de soja, pois caso aumentem os custos de produção, significativas alterações virão a acontecer. Prova disso é que se o custo de aquisição dos resíduos ultrapassar $50 \%$ do valor de mercado da soja, limite estipulado para o cenário pessimista, o custo de produção de biodiesel aferidos será superior ao preço do diesel e do biodiesel de mercado, tornando a produção inviável se analisada apenas sob o ponto de vista econômico. Isso denota o impacto significativo da soja no custo de produção, bem como a importância do ganho de escala, que neste projeto, dentre outros motivos, por ser uma usina de pequeno porte, é pouco aproveitado.

Ao final deste projeto pode-se constatar que as 1.682 toneladas anuais de resíduos de soja produzirão 387.600 litros/ano de biodiesel, viabilizando a implantação do complexo no Porto de Paranaguá, pois o Valor Presente Líquido (VPL) apresenta um montante positivo de R\$ 1.089.459,00. Isto significa que no final dos 10 anos, o valor do investimento será compensado pelo lucro obtido no decorrer dos períodos. Outro índice que indica a viabilidade do projeto é a Taxa Interna de Retorno (TIR - 27\% a.a.), que teve seu valor superior a Taxa mínima de Atratividade (TMA), que para esse tipo de empreendimento de é $7,25 \%$ ao ano. O tempo de retorno do investimento é de 5 anos, considerado relativamente longo para esse segmento.

Um dos fatores que contribuem para a implantação e viabilidade da usina é o fato de que os resíduos, além de onerosos para o porto, visto que há uma empresa contratada para descartalos, ainda não geram valor agregado. Complementando a análise determinística, a simulação de Monte Carlo demonstrou que apesar de financeiramente viável, o investimento apresenta risco financeiro de perda de capital, pois se verificou $18,8 \%$ de interação negativa do VPL, isto é, existe uma probabilidade de $18,8 \%$ do investimento não oferecer o retorno mínimo desejado.

Além das análises determinísticas e de simulação de riscos, outras considerações menos objetivas acerca desta matéria se fazem necessárias, de modo a esclarecer os valores apresentados. Diante de um panorama em que a produção nacional de biodiesel é predominantemente baseada na rota etílica, isto é, verdadeiramente renovável, abranger as cadeias produtivas do etanol e das oleaginosas constitui uma das alternativas para o processo de desenvolvimento sustentado e valorização de diversas comunidades rurais, bem como de inclusão 
social, contribuindo para a fixação do homem ao campo, gerando emprego e renda (CAMPOS, 2003).

As informações utilizadas no estudo de viabilidade e risco financeiro foram projeções para o futuro dos valores das variáveis que compõem o fluxo de caixa e, consequentemente, são estimativas sujeitas a erros. Salienta-se também que não foram consideradas neste estudo as receitas oriundas dos ganhos de imagem. Sabe-se que os resíduos sólidos representam um grande risco ao meio ambiente. Assim, a imagem positiva gerada pelo uso de um biocombustível, obtido pelo beneficiamento dos resíduos, poderia gerar receitas adicionais (créditos de carbono pela redução da emissão de gases de efeito estufa, entre outras) e reduzir os custos de produção do biodiesel. Pelo exposto, apesar de limpo e renovável, gerador de emprego e de renda, inclusive no meio rural, ainda se fazem necessários estudos acerca da viabilidade de empresas utilizarem o biodiesel como fonte de energia. Esse fato se deve porque, em alguns casos, tal biocombustível pode ficar mais oneroso do que o próprio diesel, devido ao óleo utilizado como insumo, a logística de distribuição, a instabilidade de preços da matéria-prima, além dos impostos incidentes na produção.

\section{REFERÊNCIAS}

APPA. Administração dos Portos de Paranaguá e Antonina. Plano de desenvolvimento e zoneamento PDZPO do Porto de Paranaguá, Paraná: APPA, 2012.

ANP. Agência Nacional de Petróleo, Gás Natural e Biocombustíveis. ISSN 1983-5884: anuário estatístico brasileiro do petróleo, gás natural e biocombustíveis. Rio de Janeiro, 2011.

ASSAF NETO, A.. Finanças corporativas e valor. São Paulo: Atlas, 2003.

BARBOSA, J.. Aplicações de técnicas de simulação Monte Carlo nas análises industriais. In: SIMPÓSIO BRASILEIRO DE ENGENHARIA DE AVALIAÇÕESS.10. Anais. São Paulo, 2000.

BRASIL. Ministério da Agricultura, Pecuária e abastecimento. Anuário estatístico da agroenergia, 2009. Brasília: MAPA, 2009.

CONAB. COMPANHIA NACIONAL DE ABASTECIMENTO. Série histórica de área plantada, produtividade e produção - grãos.

CAMPOS, I.. Biodiesel e Biomassa: duas fontes para o Brasil. Revista de Ecologia do Século 21, Rio de Janeiro, v.80, 2003.

COSTA, L. G. T. A.; AZEVEDO, M. C. L.. Análise fundamentalista. Rio de Janeiro: FGV/EPGE, 1996.

FERRARI, R. A.; OLIVEIRA, V. S.; SCABIO, A.. Biodiesel de soja - taxa de conversão em ésteres etílicos, caracterização físicoquímica e consumo em gerador de energia. Química Nova, v. 28, n.1, p.19-23, 2005.

GASLENE, A.; FENSTERSEIFER, J.E.; LAMB, R.. Decisões de investimentos da empresa. São Paulo: Atlas, 1999.

GITMAN, L. J.. Princípios de Administração Financeira. 12 ed. São Paulo: Pearson Prentice Hall, 2010.

HOJI, M.. Administração Financeira: uma abordagem prática. 5 ed. São Paulo: Atlas, 2006.

MEHER, L. C.; SAGAR, D. V.; NAIK, S. N.. Technical aspects of biodiesel production by transesterification.

Renewable \& Sustainable Energy Reviews, v.10, n.3, 2004. 
MURTA, A. L. S.. Análise da viabilidade de autoprodução de biodiesel por frotistas: o caso da Vale. Tese (Doutorado em Engenharia de Transportes) - Universidade Federal do Rio de Janeiro, Rio de Janeiro, 2008.

PARENTE, E. J. S.. Uma aventura tecnológica num país engraçado. Fortaleza: Unigrafica, 2003.

SANDRONI, P.. Dicionário de administração e finanças. São Paulo: Best Seller, 1996. 